\title{
OBSERVATIONS ON THE FOETUS DURING EXPERIMENTAL HYPOTHERMIA ${ }^{1}$
}

\author{
S. L. VANDEW.ATER, M.D., F.R.C.P.(c), ${ }^{2}$ and \\ W. M. PAUL, M.D., F.R.C.S. (C) $)^{3}$
}

INDUCED HYPOTHERMIA has become, in many medical centres, an accepted adjunct in anaesthesia in the direct surgical approach in subarachnoid haemorrhage due to a ruptured berry aneurysm. This has been the practice in Toronto $(1,2)$ and, up to May 1959, 161 ruptured aneurysms had been operated upon, at varying times after the last haemorrhage, at the Toronto General Hospital. In' this consecutive șeries, 91 patients were female, 26 of whom were less than 40 years of age. In 1956, Cannell and Botterell (3) reviewed a series of 12 patients with subarachnoid haemorrhage, complicating pregnancy, in six of which an aneurysm was demonstrated. Three of the six underwent common carotid ligation and survived, one had the middle cerebral $\mid$ aneurysm clipped successfully under induced hypotension (4), two died untreated, and one died following complications of arteriography. This report inspired the present work, which is an attempt to answer some of the questions on the immediate and delayed effects of hypothermia on the foetus. This may be considered an academic question, for our neurosurgical colleagues firmly believe in early operation and the use of hypothermia in the surgical treatment of subarachnoid haemorrhage.

\section{METHOD}

Observations were made on nine pregnant ewes, one to two weeks within term. The ewes, after being clipped and washed with a detergent to remove the skin oils, were given atropine $0.06 \mathrm{mg}$. intravenously, followed by thiopental sodium or pentabarbital sodium, and placed in the right lateral position. Because of the size and nature of the animals, and the presence of copious salivation, a tracheotomy was performed, and a cuffed tube inserted. A cannula was directed into the carotid artery, for mean maternal blood pressure recording and arterial sampling. The uterus was exteriorized, and the foetal circulation catheterized by the method described by Reynolds, Paul, and Huggett (5). A small incision was made in the uterus until the chorionic membrane was explosed. Branches of the umbilical cord were discovered, streatring between the amnion and the chorion, and a suitable vessel located. In this preparation a branch of the umbilical vein was catheterized and the uterine incision closed. It was thus possible to sample

iPresented to the Section of Anaesthesia, B.M.A.-C.M.A., Edinburgh, July, 19\%9:

${ }^{2}$ Associate Professor, and Head of the Department of Anaesthesia, Queen's University, Kingśton, Ontario; formerly Clinical Teacher, Department of Anaesthesia, University of Toronto.

3Associate, Department of Obstetrics and Gynaccology, University of Toronto; Dominion Stores Fellow. 
foetal blood with the foetus remaining in utero, and the membranes intact. In two experiments, the uterus was replaced in the abdominal cavity.

Maternal and foetal circulatory changes were noted, and oxygen saturation, carbon dioxide content, and $\mathrm{pH}$ estimations were made, using an Astrup apparatus.

\section{Anaesthesia}

In the first five experiments, the animals were induced with thiopental sodium (800-1,200 mg.), and anaesthesia maintained with a 50 per cent $\mathrm{N}_{2} \mathrm{O} / \mathrm{O}_{2}$ mixture. The first two of this group were allowed to breathe spontaneously, with manual assistance, and chlorpromazine ( $100 \mathrm{mg}$;) was given in divided doses to combat shivering. Because of our inability to prevent respiratory acidosis, even with vigorous manual ventilation in these two experiments, the other three animals were curarized with d-tubocurare (18-30 mg. $)^{\circ}$ and ventilated with a Jefferson positive-negative ventilator $(+.20,-12 \mathrm{~mm}$. $\mathrm{Hg}, 24-28$ respirations per minute).

In the last four experiments, anaesthesia was induced with pentobarbital sodium (1,200-1,750 mg.), followed by curarization; and artificial positive-negative ventilation, using 100 per cent oxygen.

\section{Hypothermia}

Surface cooling was carried out using chopped ice, the application of ice on or near the exteriorized uterus being avoided. Ewe rectal and amniotic fluid temperatures were recorded with an electric thermocouple. The animals were cooled approximately $10^{\circ}$ from the normal range of $39.0-39.5^{\circ} \mathrm{C}$. "Crash" rewarming was partially carried out in seven of the nine animals using hot water.

\section{Observations}

The uterus was exteriorized for three to four hours, allowing exposure to a room temperature of about $22^{\circ} \mathrm{C}$. This fact plus the taking of up to $50 \mathrm{cc}$. of blood (one-quarter of the foetal blood volume) contributed to the death of one foetus and terminal deterioration of others before crash rewarming was complete.

The maternal blood pressure was recorded as a mean pressure, and the foetal heart rate counted directly by palpation or auscultation. The blood gas, estimations are presented with some reservations, because of the difficulty in arriving at a true figure when the blood has become cooled, and the animal has been pressure ventilated with oxygen. The $\mathrm{pH}$ estimations were adjusted to the temperature at the time the blood was taken .(6). Barcroft $\mid(7)$, measuring foetal lamb oxygen saturation close to term, found values varying from 50 to 70 per cent. Reynolds and Paul (8), in similar preparations of foetal lambs at term, found the heart rate to vary from 140 to 200 per minute. In the experience of Paul (9) and Barn et al. (10), bradycardia does not usually occur until the foetal $\mathrm{O}_{2}$ saturation falls to $10-15$ per cent.

\section{Experiment I}

A moderate haemorrhage from the carotid artery occurred at 1\% hours, resulting in severe maternal hypotension. The matêrnal respiratory exchange even 


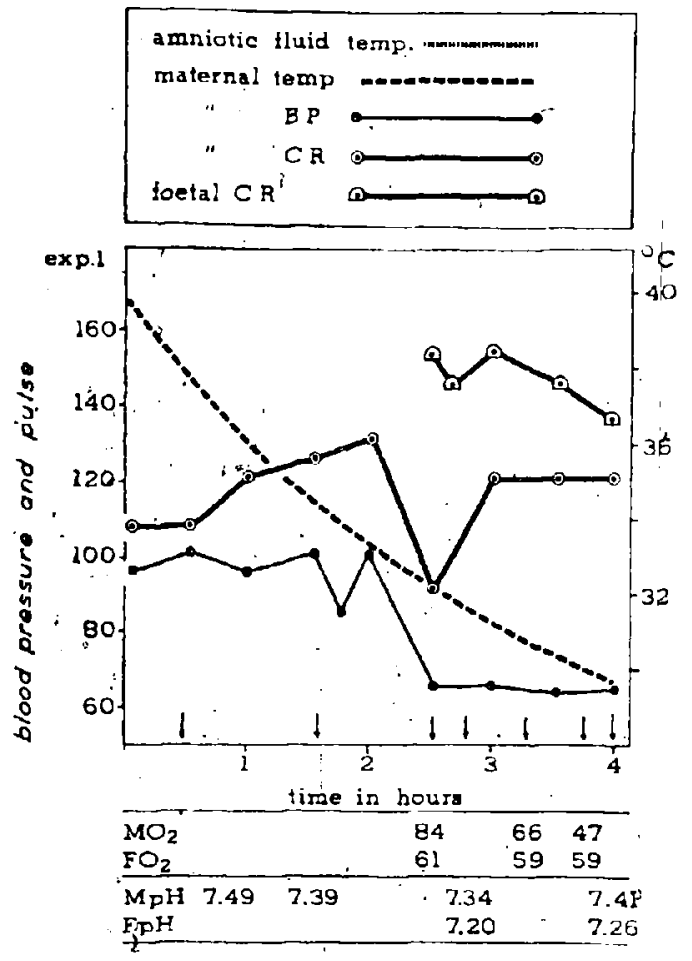

Figure 1

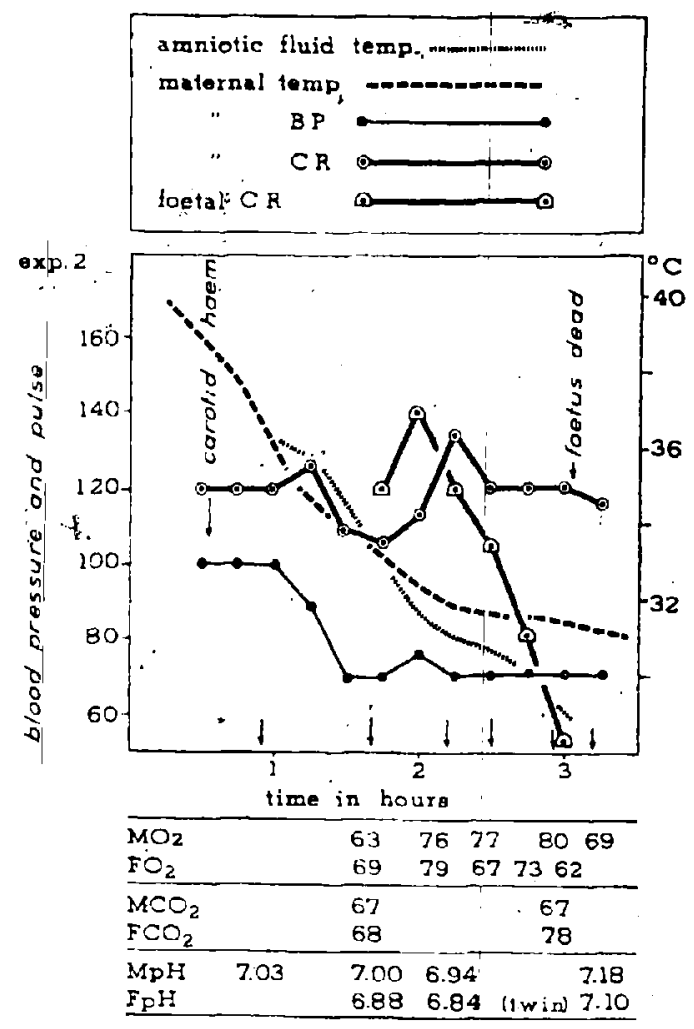

Figure 2

with vigorous manual assistance was inadequate, resulting in low maternal $\mathrm{O}_{2}$ saturation. In spite of this state of hypotension and maternal hypoxia, the foetal heart rate and $\mathrm{O}_{2}$ saturation remained within the normal range, up to the end of the experiment $11 / 2$ hours later. This was during the hypothermic period, and no rewarming was carried out. The foetal $\mathrm{pH}$ values paralleled those of the ewe, but were lower. (See Fig. 1.)

\section{Experiment II}

Gross haemorrhage occurred from a dislodged carotid cannula, resulting in maternal hypotension. Matemal respiratory exchange was inadequate (with manual assistance) leading to hypoxia and respiratory acidosis. In spite of this, the foetal $\mathrm{O}_{2}$ saturation remained high, but there was a steady decline in cardiac rate and $\mathrm{pH}$, and a rise in $\mathrm{CO}_{2}$ content. It would appear, that in this experiment the bradycardia and eventual death of the foetus were not due to foetal anoxia, but were related to maternal acidosis. (See Fig. 2.)

\section{Experiment III}

Controlled respirations with a Jefferson ventilator were carried out in this and the following experiments. The blood samples were unsuitable for gas analysis. The maternal and foetal $\mathrm{pH}$ rèadings showed a fall followed by a rise, after an increase in the respiratory pressures, and aspiration of secretions through the tracheotomy tube. The fall in foetal cardiac rate followed the $\mathrm{pH}$ changes which might suggest the effect of maternal acidosis. (See Fig. 3.) 


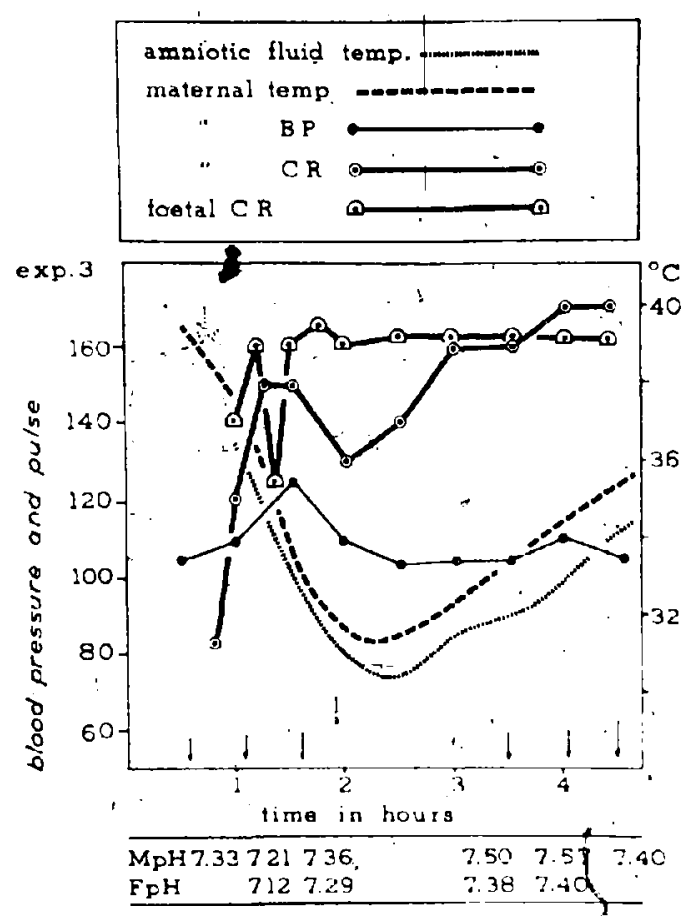

Figure 3

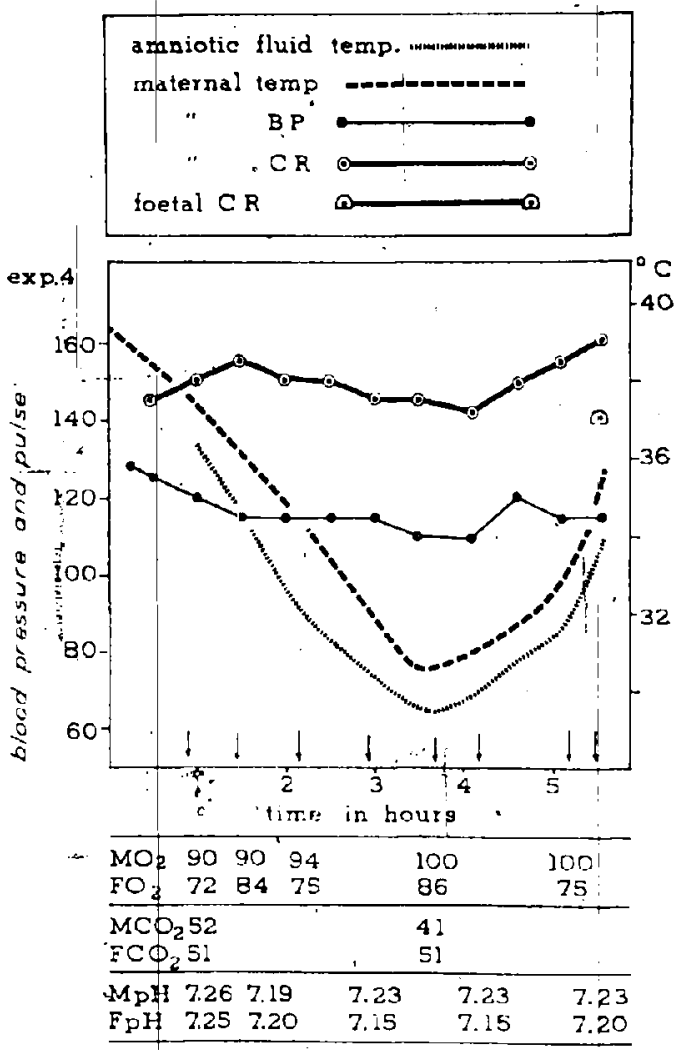

Figure 4

\section{Experiment, $1 V^{\prime}$}

The foetal pulse was not available as the uterus has been replaced in the abdomen. All figures were within normal limits except for the rather low $\mathrm{pH}$. The foetal $\mathrm{O}_{2}$ saturation figures were unusually high. (See Fig. 4.)

\section{Experiment $\mathrm{V}$}

All figures were within normal limits, except the $\mathrm{pH}$ was again rather low. The foetal $Q_{2}$ saturation figures were normal, with a normal foetal pulse rate throughout the four: hours of exposure. (See Fig. 5.)

\section{Experiment VI}

Pentobarbital sodium, curare, controlled respirations and 100 per cent $\mathrm{O}_{2}$ were used in this and in the following three experiments. The uterus was replaced in the abdomen. Rapid rewarming with hot water $\left(50^{\circ} \mathrm{C}\right.$.) resulted in a slight fall in matenal blood pressure, probably as a result of vasodilatation. The foetal $\mathrm{O}_{2}$ remained within normal limits, although the $\mathrm{CO}_{2}$ content rose and $\mathrm{pH}$ fell. The foetus survived the time of the experiment. (See Fig. 6.)

\section{Experiment VII}

There was a severe fall in maternal blood pressure and pulse rate with the onset of rewarming. The blood pressure was restored with vasoxamine, $10 \mathrm{mg}$., intravenously. The ewe was difficult to oxygenate, even with high.pressures, in 

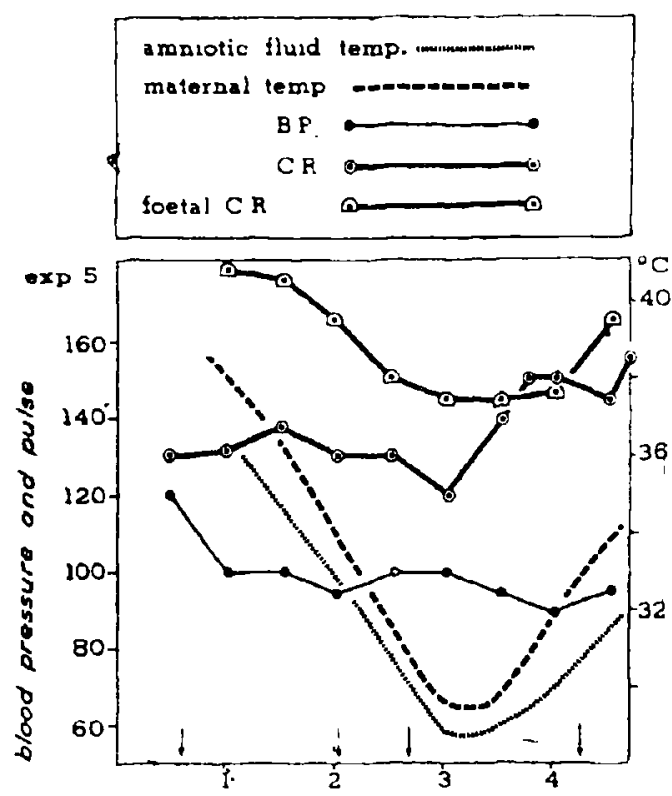

\begin{tabular}{|c|c|c|c|c|}
\hline $\begin{array}{l}\mathrm{MO}_{2} \\
\mathrm{FO}_{2}\end{array}$ & $\begin{array}{l}92 \\
71 \\
\end{array}$ & $\begin{array}{l}98 \\
78 \\
\end{array}$ & $\begin{array}{l}93 \\
72 \\
\end{array}$ & $\begin{array}{l}88 \\
75\end{array}$ \\
\hline $\begin{array}{l}\mathrm{MCO}_{2} \\
\mathrm{FCO}_{2}\end{array}$ & $\begin{array}{r}45 \\
47 \\
\end{array}$ & & $\begin{array}{l}40 \\
52 \\
\end{array}$ & \\
\hline $\begin{array}{l}\mathrm{MpH} \\
\mathrm{FpH}\end{array}$ & $\begin{array}{l}739 \\
7.18\end{array}$ & & $\begin{array}{l}7.27 \\
7.31\end{array}$ & $\begin{array}{l}721 \\
718\end{array}$ \\
\hline
\end{tabular}

Figure 5
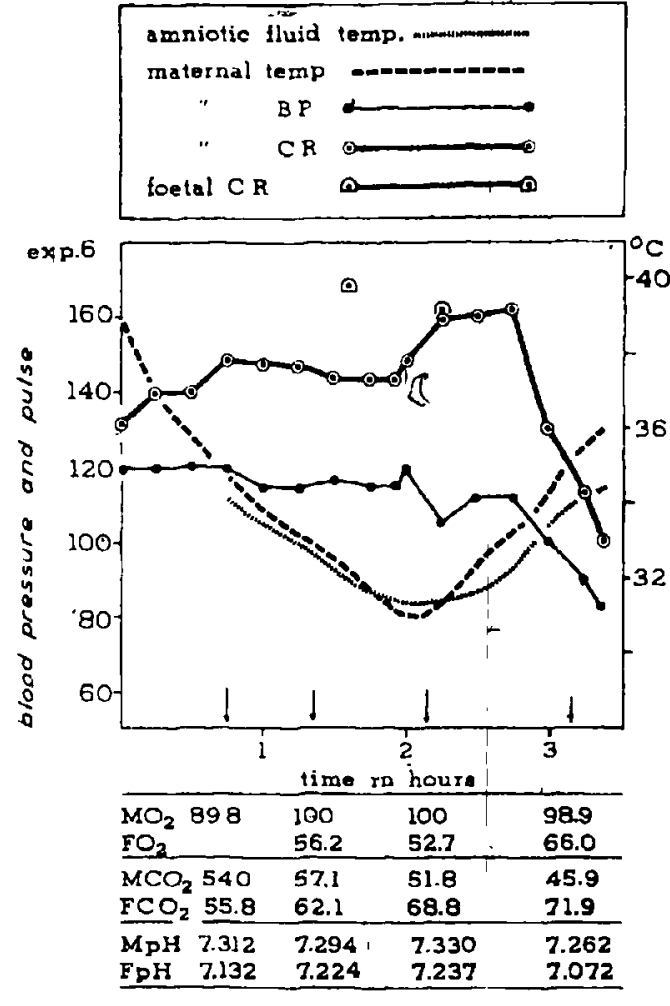

Figurx 6

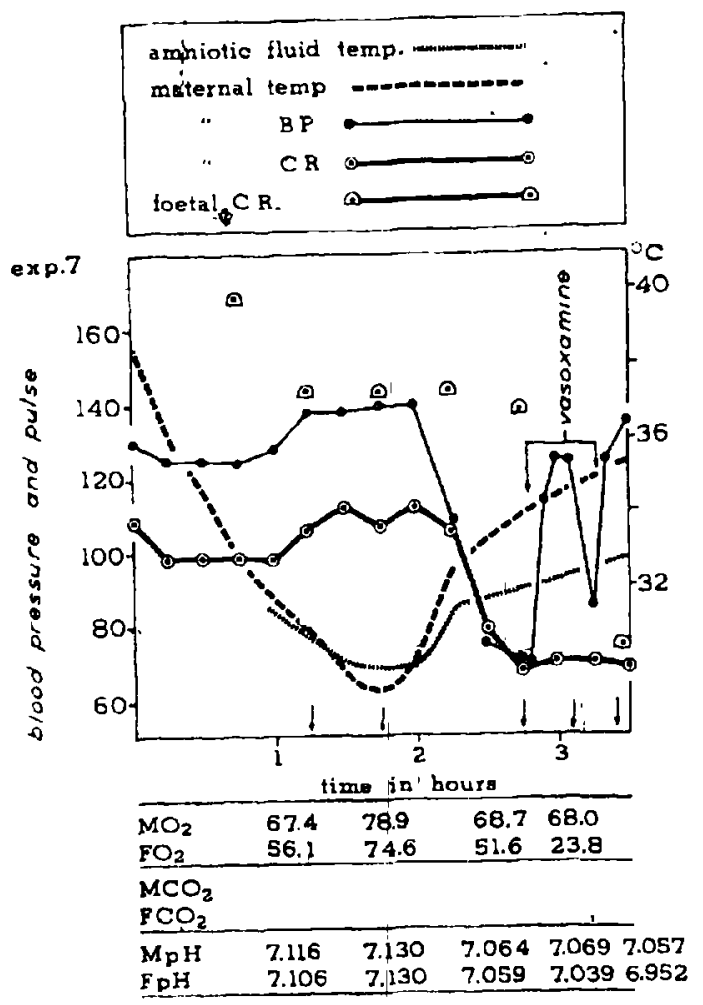

Ficune 7 

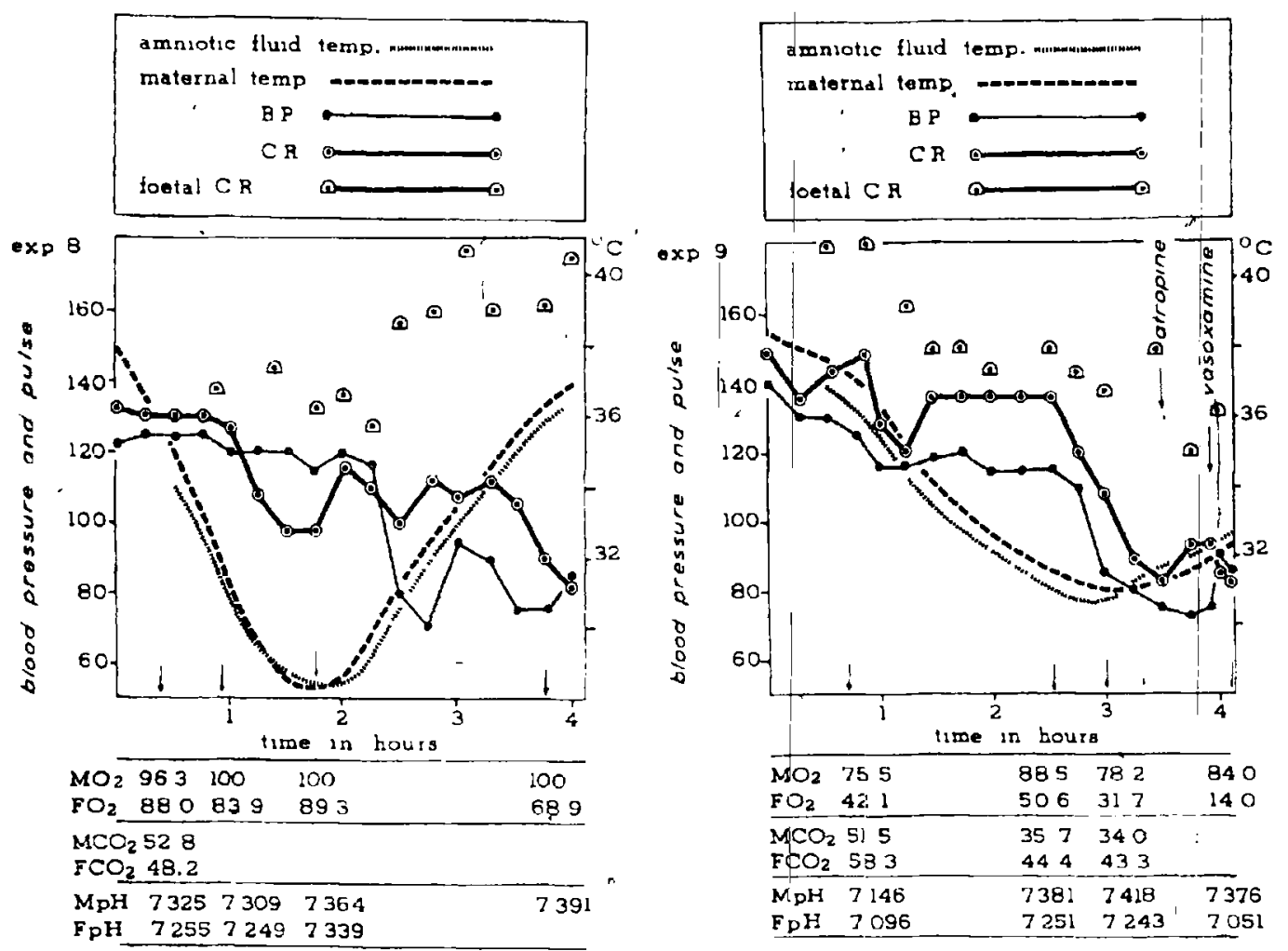

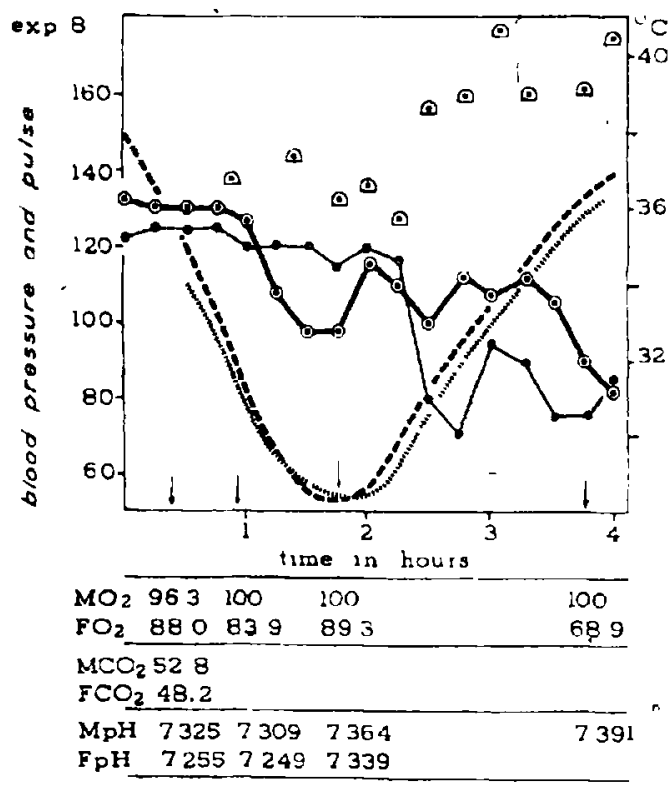

FIGURE 8

Figure 9

part due to copious secretions requiring frequent aspiration. The foetal $\mathrm{O}_{2}$ saturation was surprisingly maintained, until near the end of the experiment. Both the maternal and the foetal $\mathrm{pH}$ values were low. Measurement of $\mathrm{CO}_{2}$ content was not done. (See Fig. 7.)

\section{Experiment VIII}

There was a fall in maternal blood pressure with rewarming. All figures were normal throughout the experiment, with the foetus quite active and alive at the end. (See Fig. 8.)

\section{Experiment IX}

Again, there was a severe fall in maternal blood pressure and pulse rate with rewarming. Both maternal and foetal $\mathrm{O}_{2}$, saturations were low, with the foetus deteriorating towards the end of the experiment. The $\mathrm{CO}_{2}$ determinations were normal. The $\mathrm{pH}$ values increased during cooling, but the foetal $\mathrm{pH}$ was quite low at the final reading. The foetus survived the experiment, but was in poor condition. (See Fig. 9.)

\section{Discussion}

Maternal respiratory acidosis and hypoxia could only be prevented by using relatively high inflationary pressures with an automatic respirator in a curarized pregnant sheep lying on its side. Hypotension from haemorrhage, with adequate oxygenation did not adversely affect foetal heart rate or $\mathrm{O}_{2}$ saturation. However 
maternal hypotension which occurred with rapid rewarming presumably due to pertpheral vascular dilatation, was usually accompanied by a falling foetal $\mathrm{O}_{2}$ saturation. Changes in foetal $\mathrm{O}_{2}$ saturation, $\mathrm{CO}_{2}$ content, and $\mathrm{pH}$ generally accompanied similar changes in the ewe. When measurements in the ewe were normal, the foetal $\mathrm{O}_{2}$ saturation was well above the recognized normal level. Respiratory acidosis in the ewe appeared to cause severe bradycardia and death of one foetus, even when the foetal $\mathrm{O}_{2}$ saturation was normal, and there was a suggestion of foetal distress (slowing heart rate) in a second (Experiment III).

The obsirvations on the sheep foetus were acute experiments, and no attempt was made to save the animals. A brief study on the possible long-term effects of hypothermia was carried òut with a series of guinea pigs.

Foetal survival studies following single episodes of hypothermia were carried out in the guinea pig in mid- and late pregnancy (Table I). Body temperatures

TABLE I

\begin{tabular}{lccc}
\hline & No. animals & Total litter & $\begin{array}{c}\text { Litter } \\
\text { survival (1 wk.) }\end{array}$ \\
\hline $\begin{array}{l}\text { No hypothermia } \\
\text { Hypothermia at }\end{array}$ & 16 & - & 61 \\
$\begin{array}{c}55-65 \text { days } \\
\text { gestation }\end{array}$ & 6 & (average 3.8 per animal) & 57 \\
$\begin{array}{c}\text { Hypothermia at } \\
\text { 30-40 days } \\
\text { gestation }\end{array}$ & 8 & $\begin{array}{c}25 \\
\text { (avẹrage } 4.1 \text { per animal) }\end{array}$ & 24 \\
\hline
\end{tabular}

were lowered $10-12^{\circ} \mathrm{C}$. by immersion of the unanaesthetized animals in ice water. A comparison of litter size and survival was made between this group and control animals in the same colony. It is noted that single episodes of hpothermia of this degree did not alter size or survival in these animals.

\section{Cònclusions}

No conclusions can be made from these limited experiments. However, we might infer that foetal distress occurred during hypothermia with the occurrence of maternal respiratory acidosis and hypoxia, and with gross maternal hypotension due to peripheral vascular dilatation from rapid surface rewarming. It would appear that well-conducted anaesthesia and hypothermia may be a safe procedure for the foetus.

\section{REFERENCES}

1. Botterell, E. H.; Lougheed, W. M.; ScotT, J. E.; \& Vanpewater, S. L. Hypothermia, and Interruption of Carotid or Carotid and Vertebral Circulation, in the Surgical Magnagement of Intracranial Aneurysm. J. Neurosurg. 13: 1 (1956).

2. Botreflell, E. H.; Lougheed, W. M.; Mordix, T. P.; \& Vandewater, S. L. Hypothermia in the Surgical Treatment of Ruptured Intracranial Aneurysms. J. Neurosurg. 15: 4 (1958).

3. Cannell, D. E.; \& Botrereld, E. H. Subarachnoid Haemorrhage and Pregnancy. Am. J. Obst. \& Gynec. $72: 844$ (1958). 
4. Vandewaten, S. L. The Use of Hypotension and Hypothermia in Subarachnoid Haemorrhage. Symposium on "Pathogenesis and Treatment of Cerebral Vascular Disease," vol. 5, Houston Neurological Society, Houston, Texas. Springfield, Ill.: Charles C. Thomas, in publication (1959).

5. Reynolds, S. R. M., PaUL, W. M., \& Huggetr, S. St. G. Physiological Study of the Monkey Foetus in utero. Bull. Johns Hopkins Hosp. 95: 256 (Nov. 1954).

6. Craig, F. A.; Lange, K.; Orerman, J.; \& Carson, S. A Simple Accurate Method of Blood pH Determination for Clinical Use. Arch. Biochem. Biophys. 38: 257 (1952).

7. Barcroft, Sir Josern. Researches in Prenatal Life, vol. 1. London: Blackwell Scientific Publications (1946).

8. Reynolds, S. R. M., \& Paul, W. M Relation of Bradycardia and Blood Pressure of the Foetal Lamb-in-utero to Mild and Severe Hypoxia. Am. J. Physiol. 193: 249 (1958).

9. PaUL, W. M. A Mechanism of Bradycardia in the Foetal Lamb-in-utero. Bull Johns Hopkins Hosp. 99: 357 (Dec. 1956).

10. Bons, G. V.'R., Dawes, G. S., \& MotT, J. C.' Oxygen Lack and Autonomic Nervous Control of the Foetal Circulation in the Lamb. J. Physiol, 134: 149 (Oct. 1956). 